\title{
Mercury stress resistances in Nauclea orientalis seedlings inoculated with arbuscular mycorrhizal fungi
}

\author{
Hanna Artuti Ekamawanti ${ }^{1,2}$, Yadi Setiadi ${ }^{3}$, Didy Sopandie ${ }^{4}$, Dwi Andreas Santosa ${ }^{5}$ \\ ${ }^{1}$ Tropical Silviculture Major, Post-graduate School of Bogor Agricultural University, Bogor, Indonesia \\ ${ }^{2}$ Faculty of Forestry, Tanjungpura University, Pontianak, Indonesia \\ ${ }^{3}$ Laboratory of Forest Biotechnology, Research Center for Biological Resources and Biotechnology, Bogor Agricultural University, Bogor, \\ Indonesia \\ ${ }^{4}$ Department of Agronomy and Horticulture, Bogor Agricultural University, Bogor, Indonesia \\ ${ }^{5}$ Magister Study Program on Soil and Environmental Biotechnology, Department of Soil and Land Resources, Bogor Agricultural \\ University, Bogor, Indonesia
}

\section{Email address:}

hanna.artuti@gmail.com (H. A. Ekamawanti),ysetiad55@gmail.com (Y. Setiadi), didysopandie@gmail.com (D. Sopandie), dsantosa@indo.net.id (D. A. Santosa)

\section{To cite this article:}

Hanna Artuti Ekamawanti, Yadi Setiadi, Didy Sopandie, Dwi Andreas Santosa. Mercury Stress Resistances in Nauclea Orientalis Seedlings Inoculated with Arbuscular Mycorrhizal Fungi. Agriculture, Forestry and Fisheries. Vol. 3, No. 2, 2014, pp. 113-120. doi: 10.11648/j.aff.20140302.20

\begin{abstract}
The effect of inoculation with the arbuscular mycorrhizal (AM) fungi on the resistance of mercury (Hg) in lonkida (Nauclea orientalis) seedlings were investigated using an artificially contaminated river sand media at the concentration of 0,375 and $750 \mu \mathrm{M} \mathrm{Hg}$ at screen house. Mercury accumulation was lower in mycorrhizal roots than in non-mycorrhizal roots when $\mathrm{Hg}$ was added at the rates of $750 \mu \mathrm{M}$. However, $\mathrm{Hg}$ accumulation and its translocation to the leaves were very low, either in mycorrhizal or non-mycorrhizal seedlings. The amount of $\mathrm{Hg}$ retained in roots was higher than in leaves, irrespective of applying different $\mathrm{Hg}$ concentration. $N$. orientalis seedlings have a high tolerance to $\mathrm{Hg}(>70 \%)$. Under these experimental conditions, $N$. orientalis shows a high resistance and capacity to retain $\mathrm{Hg}$ in roots. Mycorrhizal symbiosis showed a significant effect of the resistance to $\mathrm{Hg}$ of $\mathrm{N}$. orientalis plants grown in Hg-polluted and $\mathrm{Hg}$-unpolluted media. Furthermore, the beneficial effects of the AM fungi observed in this study aroused an interest in considering the role of AM fungi in plant-based strategies of remediation of highly $\mathrm{Hg}$-polluted soils.
\end{abstract}

Keywords: Nauclea Orientalis, Mercury, Resistance, Arbuscular Mycorrhizal Fungi, Remediation

\section{Introduction}

Mercury is ranked third on The Agency for Toxic Subtances and Disease Registry (ATSDR) 2011 Substance Priority List - a listing algorithm prioritizes substances based on frequency of occurrence at National Priorities List (NPL) sites - toxicity and potential for human exposure to the substances found at NPL sites [1]. Anthropogenic activities and the agricultural soils because of the annual import of toxic $\mathrm{Hg}$ [2]. $\mathrm{Hg}^{2+}$ causes toxicity symptoms in higher plants through adverse effects on biochemical and physiological process [2], reduces chlorophyll levels in leaves [3] and disturbs photosynthetic activity [4]. Change in uptake and translocation of mineral nutrients have been reported in the presence of $\mathrm{Hg}$ [5]. In addition, $\mathrm{Hg}$ triggers oxidative stress by inducing production of $\mathrm{H}_{2} \mathrm{O}_{2}$, lipid peroxide, and reactive oxygen species (ROS) in many plants, such as tomato, cucumber and alfalfa [6,7].

The use of plants and soil microbes for remediation of $\mathrm{Hg}$-polluted is an emerging area of interest because it provides an ecologically sound and safe method. It has been proposed that plants can be used to remediate soils polluted with such element, either by stabilization, extraction, and volatilization [8-10]. Plants species selection is a key aspect for the sucess of remediation soils polluted and long-term reclamation of degraded lands. $\mathrm{Hg}$ accumulation in several plants has been studied, such as white clover [11], alfalfa [12], lentil, chickpea [13] and common vetch [14]. However, very few studies have been conducted on the $\mathrm{Hg}$ accumulation in tropical trees, such as Nauclea orientalis. $N$. orientalis is a pioneer species, a hardy species with dry land reclamation potential, and gives 
some services to the environment, such as to controls soil loss on riparian areas (erosion control), and soil improver because leaf litter on decay replenishes soil fertility [15]. If this tree species is proposed for phytoremediation on $\mathrm{Hg}$-polluted soil, plant $\mathrm{Hg}$ uptake and resistance response should be evaluated under controlled conditions, prior to field establishment a screen to identify suitable candidate species.

An alternative solution is to combine the advantages of microbe plant symbiosis in the plant rhizosphere into an effective clean-up technology. Arbuscular mycorrhizal (AM) fungi are ubiquitous soil, forming symbiotic associations with roots of the majority of plant species [16]. It has been addressed that mycorrhizal inoculation can affect the accumulation of metals such as $\mathrm{Cu}, \mathrm{Cd}, \mathrm{Zn}$, and $\mathrm{As}$ by plants and enhance the tolerance of host plants to contamination of these metals in soil [17-19]. However, the behavior of $\mathrm{Hg}$ in mycorrhizal plants is still lack and the potential of AM fungi has not yet been fully explored with respect to its $\mathrm{Hg}$ phytoremediation potentials. The first report about the effects of mycorrhizal inoculation on $\mathrm{Hg}$ behavior in soil-plant system is done [20] and it has been shown that $\mathrm{Hg}$ uptake was lower by mycorrhizal roots of maize than by non-mycorrhizal roots.

The interaction between AM fungi, tree species (such as $N$. orientalis) and $\mathrm{Hg}$ was the subject of this study because of the possibility of the beneficial effect of mycorrhizae in improving the resistance of plants against $\mathrm{Hg}$ toxicity. The study was carried out to determine the resistance to $\mathrm{Hg}$ stress in $N$. orientalis seedlings inoculated with AM fungi grown on artificial $\mathrm{Hg}$-polluted river sands media in pot experiment. Such knowledge would help clarify the potential of tree species ( $N$. orientalis) and AM fungi as phytoremediation agents of $\mathrm{Hg}$-polluted soils.

\section{Materials and Methods}

\subsection{Plant Culture in River Sands at Different Rates of Hg}

Eleven-months old seedlings of non-mycorrhizal and mycorrhizal $N$. orientalis were obtained from the nursery. Each plant was grown in a PVC pot $(10 \mathrm{~cm}$ in diameter and $30 \mathrm{~cm}$ in height), containing $5 \mathrm{~kg}$ coarse river sands (1-2 $\mathrm{mm})$ as substrate. Mycorrhizal inoculum (25 g) (Laboratory of Forest Biotechnology, Research Center for Biological Resources and Biotechnology, Bogor Agricultural University collection) was inoculated to mycorhizal seedlings for second inoculation and sterilized mycorrhizal inoculum $(25 \mathrm{~g})$ and its filtrate $(10 \mathrm{~mL}$ each pot) was applied to non-mycorrhizal seedlings. All seedlings were maintained by adding the nutrient solution for 8 weeks. The composition of the nutrient solution was as follows (mmol L-1) [21]: $\mathrm{Ca}\left(\mathrm{NO}_{3}\right)_{2}$ 1.5; $\mathrm{KNO}_{3} 4.0$; $\mathrm{KH}_{2} \mathrm{PO}_{4} 1.5$ and $\mathrm{MgSO}_{4}$ 1.0. Micronutrients were supplied $\left(\mu \mathrm{mol} \mathrm{L}{ }^{-1}\right)$ : Fe-EDDHA 36; $\mathrm{MnSO}_{4} \cdot \mathrm{H}_{2} \mathrm{O} 33$; $\mathrm{ZnSO}_{4} .7 \mathrm{H}_{2} \mathrm{O}$ 1.6; $\mathrm{CuSO}_{4} .5 \mathrm{H}_{2} \mathrm{O} \quad 1.6 ; \mathrm{H}_{3} \mathrm{BO}_{3} 46$ and $\left(\mathrm{NH}_{4}\right)_{6} \mathrm{Mo}_{7} \mathrm{O}_{24} \cdot 4 \mathrm{H}_{2} \mathrm{O}$ 0.1. The $\mathrm{pH}$ of nutrient solution ranged for 5.5 to 6.0. A factorial experiment with completely randomized design with three replicates for each treatment was used. $\mathrm{Hg}$ treatments were 0,375 and $750 \mu \mathrm{M}$, supplied as $\mathrm{HgCl}_{2}$ salt and applied to $N$. orientalis seedlings, either with or without AM fungi inoculation treatments. The experiment was carried out in screen house of Forest Microbiology Laboratory, Research Center of Rehabilitation and Forest Conservation, Bogor, under the following conditions: $28^{\circ} \mathrm{C}-33^{\circ} \mathrm{C}$ temperature and $80 \%-95 \%$ humidity.

\subsection{Harvesting}

Plants were harvested after 30 days to $\mathrm{Hg}$ exposure and divided into roots, stems and leaves. All plant material was thoroughly washed with tap water followed by a subsequent rinse in $20 \mathrm{mM}$ EDTA solution for 1 minute and then in deionized water for 2 minutes. Total fresh weight of each tissue was determined, then a representative plants were oven-dried to constant weight at $70^{\circ} \mathrm{C}$ for 3 days prior to preparation for measuring dry weights and nutrients analysis, and at $50^{\circ} \mathrm{C}$ before preparation for $\mathrm{Hg}$ analysis. The rest of the material plants was frozen in liquid $\mathrm{N}_{2}$ and stored at $-20^{\circ} \mathrm{C}$ before chlorophyll and malondialdehyde (MDA) concentration analyzing. Water content was determined based on the difference of fresh weight and dry weight.

\subsection{Analytical Determination}

Dried plant sample was acid digested using $25 \mathrm{~mL}$ of deionized water, $3.5 \mathrm{~mL}$ of concentrated $\mathrm{HNO}_{3}$ and $0.5 \mathrm{~mL}$ of $\mathrm{HClO}_{4}$, added to $0.5 \mathrm{~g}$ dry weight (DW) in a test tube. The digested solution was analyzed for mercury concentration using inductively coupled plasma-optical emission spectrometry (ICP-OES, Spectro Genesis) excitation, and calibration was performed by using standard $\mathrm{Hg}$ solution [22]. Total $\mathrm{Hg}$ and nutrient $(\mathrm{P}, \mathrm{Ca}$ and $\mathrm{Mg}$ ) concentration were determined by ICP-OES. Chlorophylls was extracted and estimated according to Arnon in [23]. Lipid peroxidation in plant tissues was based on an estimate of malondialdehyde (MDA) concentration, as described by Heath and Packer in [12]. Mycorrhizal colonization was determined following [24].

\subsection{Calculation and Statistical Analysis}

Some variables were calculated to study the resistance to mercury stress of $N$. orientalis seedlings [7, 25]:

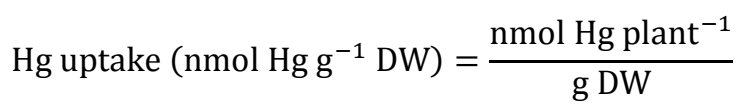

where DW is the entire-plant dry weight.

Hg translocation $\left(\right.$ nmol Hg g $\left.^{-1} \mathrm{DW}\right)=\frac{\text { nmol Hg leaves }^{-1}}{\mathrm{~g} \mathrm{DW}^{-1}}$

where DW is the entire-plant dry weight.

Concerning uptake and translocation, the same procedure 
was used for $\mathrm{P}, \mathrm{Ca}$, and $\mathrm{Mg}$ [25]. Tolerance index (TI) of mycorrhizal and non-mycorrhizal seedlings to $\mathrm{Hg}$ treatments were determined based on roots dry weight [26], as:

$$
\mathrm{TI}(\%)=\frac{\mathrm{DW} \text { of roots at } \mathrm{Hg} \text { treated }}{\mathrm{DW} \text { of roots at non Hg treated of the same treatments }} \times 100
$$

A statistical analysis for means comparison was carried out using ANOVA and least significant difference (LSD) test with CoStat 6.400 .

\section{Results and Discussions}

\subsection{Mercury Accumulation by N. Orientalis Seedlings}

$\mathrm{Hg}$ accumulation in roots of $N$. orientalis seedlings was significantly increased consistently with increasing of $\mathrm{Hg}$ rates (Table 1), either within non-mycorrhizal or mycorrhizal seedlings. $\mathrm{Hg}$ concentration in the roots was 53- to 1,633-fold and $\mathrm{Hg}$ content in the roots was 45- to 1,513-fold higher than the control (without $\mathrm{Hg}$ treatment). In line with this, $\mathrm{Hg}$ accumulation in roots was 4 - to 10 -fold the concentration found in shoots of several plant species such as B. chinensis [7], Brassica napus [27] and Zea mays [28].

However, at the $750 \mu \mathrm{M}$ of $\mathrm{Hg}$ treatment, $\mathrm{Hg}$ accumulation in roots of mycorrhizal seedlings was significantly decreased by $87 \%$ of $\mathrm{Hg}$ concentration and $84 \%$ of $\mathrm{Hg}$ content when compared to control (non-mycorrhizal plants). This result shows that at the highest concentration of $\mathrm{Hg}$, the $\mathrm{AM}$ fungi could limit $\mathrm{Hg}$ store in roots. This is in agreement with [20] result that mycorrhizal inoculation significantly decreased $\mathrm{Hg}$ concentration in maize roots with $\mathrm{Hg}$ at the rates of 2.0 and $4.0 \mathrm{mg} \mathrm{kg}^{-1}$. Hyphae of AM fungi, which contain free amino, hydroxyl, carboxyl, and other groups [16], colonize outside and inside the roots. Outside the roots, the hypahe and root surface could adsorp $\mathrm{Hg}$ so that $\mathrm{Hg}$ translocation into roots could be inhibited, and inside the roots, it change cell wall components of plant, hence possibly enhancing the sequestration of $\mathrm{Hg}$ [20]. In line with this, buffering heavy metal-stress had been assigned, at least partly, to selective immobilization of heavy metals in those root tissues that contain fungal structures [29] or to the high metal sorption capacity of the extraradical mycelium of AMF [30].

This finding supports results from numerous studies reporting that AM fungi often protect plants against high accumulation of toxic elements in the shoots, as it was reported for $\mathrm{Cu}$ [17], $\mathrm{Al}$ [31], $\mathrm{Cd}$ [17,32], $\mathrm{Zn} \mathrm{[33],} \mathrm{Pb}$ [17,34], U [35] and As [36]. In addition, glomalin, an insoluble glycoprotein which is contained in hyphae and spores of AM fungi, had a high binding capacity for $\mathrm{Cu}, \mathrm{Cd}$ and $\mathrm{Pb}$ [17], hence it could act as a biostabilizer for the remediation of polluted soils. Glomalin could be considered for $\mathrm{Hg}$ sequestration in hyphae and spores of AM fungi as well. This presumption need to be investigated in further research.

Table $1 . \mathrm{Hg}$ concentration and $\mathrm{Hg}$ content in roots and leaves of $\mathrm{N}$. orientalis seedlings grown for 30 days in river sands treated with different $\mathrm{Hg}$ concentrations and mycorrhizal inoculation.

\begin{tabular}{|c|c|c|c|c|}
\hline $\mathbf{H g}(\mu \mathrm{M})$ & Without & $\begin{array}{l}\text { Arbuscular mycor } \\
\text { With } \\
\end{array}$ & Without & With \\
\hline & \multicolumn{4}{|c|}{$\mathrm{Hg}$ concentration ( $\mathrm{ng} \mathrm{Hg} \mathrm{g}^{-1} \mathrm{DW}$ ) } \\
\hline 0 & $0.42 \pm 0.13 \mathrm{~d}$ & $2.06 \pm 0.87 \mathrm{c}$ & nd & nd \\
\hline 375 & $423.43 \pm 74.90 \mathrm{a}$ & $383.37 \pm 121.10 \mathrm{ab}$ & nd & $0.13 \pm 0.13$ \\
\hline \multirow[t]{2}{*}{750} & $685.99 \pm 16.82 \mathrm{a}$ & $109.09 \pm 23.79 \mathrm{~b}$ & $2.10 \pm 1.34$ & $8.00 \pm 0.96$ \\
\hline & \multicolumn{4}{|c|}{$\mathrm{Hg}$ content $(\mathrm{ng} \mathrm{Hg})$} \\
\hline 0 & $3.14 \pm 1.02 \mathrm{~d}$ & $14.62 \pm 5.03 \mathrm{c}$ & nd & nd \\
\hline 375 & $2900.04 \pm 1112.77 \mathrm{a}$ & $2307.52 \pm 991.22 \mathrm{ab}$ & nd & $0.53 \pm 0.53$ \\
\hline 750 & $4749.53 \pm 1707.50 a$ & $651.13 \pm 161.07 b$ & $12.44 \pm 7.46$ & $51.92 \pm 10.35$ \\
\hline
\end{tabular}

Significant differences among $\mathrm{Hg}$ treatments are indicated by different letter (mean $\pm \mathrm{SE}, \mathrm{n}=3$; LSD's test, $\mathrm{p}<0.05$ ). nd = not detected

The very small of $\mathrm{Hg}$ concentration and content in leaves of $N$. orientalis, either in non-mycorrhizal or mycorrhizal seedlings, showed that $\mathrm{Hg}$ accumulation in leaves was inhibited (Table 1). However, there is a tendency that $\mathrm{Hg}$ concentration and $\mathrm{Hg}$ content were higher in leaves of mycorrhizal seedlings than non-mycorrhizal seedlings when the highest $\mathrm{Hg}$ was applied. This result indicates that AM fungi play an important role in accumulation of $\mathrm{Hg}$ in plant.

$\mathrm{Hg}$ uptake by seedlings and $\mathrm{Hg}$ translocation of root to shoot were very limited as well (Table 2 ). These results are in agreement with previous studies [37], that roots were the main organs for $\mathrm{Hg}$ retention in Halimione portulacoides. Various studies have indicated that only a very small amount of $\mathrm{Hg}$ is translocated to plant shoot after root uptake and $\mathrm{Hg}$ in shoots mainly comes from the uptake of air $\mathrm{Hg}[7,11,38,39]$. Metal retention in roots can be a strategy for protecting the more sensitive aerial parts from the deleterious effects induced by metal stress [40] and it has been reported that in most plant species, metal ions are preferably retained in root tissues and only small portions are translocated to leaves. $\mathrm{Hg}$ accumulated by mycorrhizal and non-mycorrhizal seedlings was mostly distributed in root tissues, suggesting that an exclusion strategy for $\mathrm{Hg}$ 
tolerance widely exists in them. In addition, evaporation of $\mathrm{Hg}$ from soil/growth medium to atmosphere was promoted by mycorrhizal treatment [20].

\subsection{Effects on Plant growth and Nutrient Distribution}

Early and direct phytotoxic symptoms of heavy metals, such as $\mathrm{Hg}$, are the reduction in cell proliferation and inhibition of growth, and are frequently used as a phytotoxic index, followed by analyzing several physiological parameters $[41,42]$. $\mathrm{Hg}$ treatment caused no significant differences in biomass (fresh and dry weight of plants) and water content in non-mycorrhizal and mycorrhizal seedlings of $N$. orientalis, when compared to the control (without $\mathrm{Hg}$ treatment) (data not shown). It means that there was not a reduction of plant growth caused by $\mathrm{Hg}$ application up to $750 \mu \mathrm{M}$ during 30 days of $\mathrm{Hg}$ exposure. In line with observations on growth, the non-mycorrhizal and mycorrhizal seedlings have a high tolerance to $\mathrm{Hg}(>70 \%)$ (Table 3 ). There were not toxicity symptoms in $N$. orientalis seedlings grown for 30 days after $\mathrm{Hg}$ exposure.

Table 2. Hg uptake and translocation in N. orientalis seedlings grown for 30 days in river sands treated with different Hg concentrations and mycorrhizal inoculation.

\begin{tabular}{|c|c|c|c|c|}
\hline \multirow{2}{*}{$\mathbf{H g}(\mu \mathrm{M})$} & \multicolumn{4}{|c|}{ Arbuscular mycorrhizal inoculation } \\
\hline & Without & With & Without & With \\
\hline & \multicolumn{2}{|c|}{ Hg uptake* $\left(\mathrm{nmol} \mathrm{g}^{-1} \mathrm{DW}\right)$} & \multicolumn{2}{|c|}{$\mathrm{Hg}$ translocation* $\left(\mathrm{nmol} \mathrm{g}^{-1} \mathrm{DW}\right)$} \\
\hline 0 & nd & nd & nd & nd \\
\hline 375 & nd & nd & nd & nd \\
\hline 750 & $0.016 \pm 0.006$ & $0.040 \pm 0.005$ & $0.003 \pm 0.002$ & $0.013 \pm 0.001$ \\
\hline
\end{tabular}

* Mean \pm SE, $\mathrm{n}=3$; nd $=$ not detected

Roots of inoculated plants were extensively colonized by AM fungi, while non-inoculated controls remained non-mycorrhizal (Table 3). The percentage of AM colonization was slightly reduced in the presence of $\mathrm{Hg}$ in river sands substrate. This result indicates that the concentrations of $\mathrm{Hg}$ in the substrate was slightly harm to
AM fungi. Reference [26] reported that sensitivity of AM symbionts to heavy metal contaminated soil expressed as a reduction in root colonization. In contrast, [20] reported that addition of $\mathrm{Hg}$ in soil did not significantly influence root colonization rate in maize.

Table 3. Tolerance index and AM colonization of $N$. orientalis seedlings grown for 30 days in river sands treated with different Hg concentrations and mycorrhizal inoculation.

\begin{tabular}{|c|c|c|c|c|}
\hline \multirow{2}{*}{$\mathbf{H g}(\mu \mathrm{M})$} & \multicolumn{4}{|c|}{ Arbuscular mycorrhizal inoculation } \\
\hline & Without & With & Without & With \\
\hline & \multicolumn{2}{|c|}{ Tolerance index* $(\%)$} & \multicolumn{2}{|c|}{ AM colonization $(\%)$} \\
\hline 0 & 100.0 & 100.0 & 0 & 78.1 \\
\hline 375 & 89.1 & 71.1 & 0 & 66.0 \\
\hline 750 & 95.9 & 77.2 & 0 & 58.5 \\
\hline
\end{tabular}

* The tolerance index was based on root dry weight
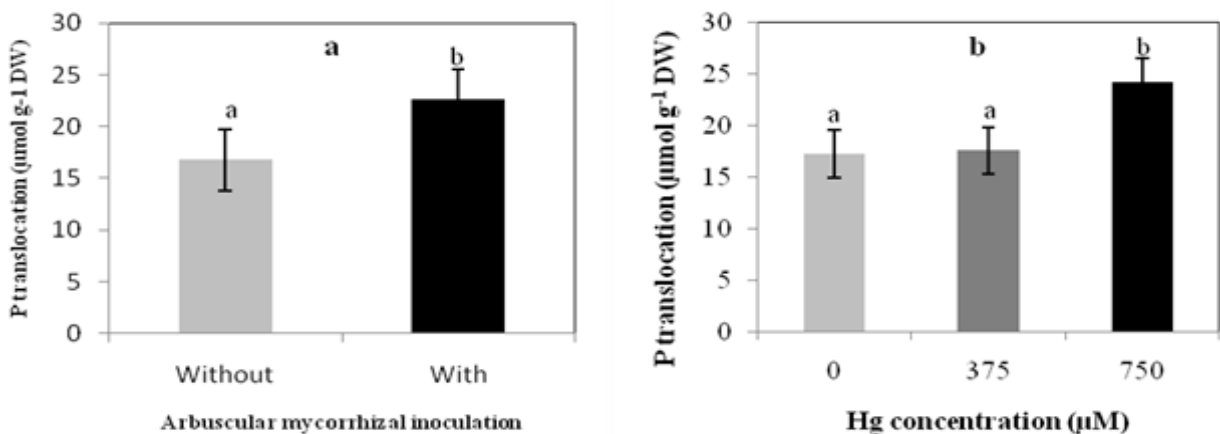

Hg concentration $(\mu \mathrm{M})$

Figure 1. P translocation in seedlings of $N$. orientalis treated with arbuscular mycorrhizal inoculation $(a)($ mean $\pm S E$, $n=9)$ and different Hg concentration (b) (mean $\pm S E, n=6)$. Significant difference among Hg treatments and AM inoculation are indicated by different letter (LSD's test, $p<0.05)$.

Another interesting result in Table 3 was that the presence of AM fungi could increased $8.6 \%$ of tolerance index of seedlings treated with $750 \mu \mathrm{M} \mathrm{Hg}$ compared with seedlings treated with $375 \mu \mathrm{M}$. This result emphasizes that AM fungi could be potentially effective in protecting seedlings exposed to high levels of $\mathrm{Hg}$ concentration. The AM fungi ability to alleviate heavy metals stress of plants grown in heavy metal contaminated soil was previously proved by [31,43]. The highly AM colonization in seedlings treated with $\mathrm{Hg}$ indicated that $\mathrm{AM}$ fungi still function in $\mathrm{Hg}$ substrate.

In addition, AM fungi still affected uptake and 
translocation of nutrients ( $\mathrm{P}, \mathrm{Ca}$ and $\mathrm{Mg}$ ) as well. $\mathrm{P}$ translocation was increased significantly in seedlings treated with AM inoculation as single factor (Fig. 1A). AM fungi increased P translocation in plant 35\% higher than control (without AM inoculation). Previous research reported that AM fungus (Glomus mosseae) increased the absorption of $\mathrm{P}$ for plant growth on red clover (Trifolium pratense) treated with different $\mathrm{Zn}$ rate levels [44].

On the other hand, $\mathrm{P}$ translocation to leaf was significantly increased $40 \%$ in seedlings treated with the highest of $\mathrm{Hg}$ application (Fig. 1B), higher than control (without $\mathrm{Hg}$ ). This result indicates that increasing $\mathrm{P}$ translocation to leaf was induced by the highest of $\mathrm{Hg}$ application. In addition, AM inoculation caused significantly increased in $\mathrm{Ca}$ and $\mathrm{Mg}$ uptake and translocation of $N$. orientalis treated with the highest of $\mathrm{Hg}$ application (Table 4). Nutrient uptake and translocation to shoot depend on water movement in xylem, and a reduction of water absorption could also disturb micronutrients distribution [5]. Water content in each tissue of seedlings did not decrease during $\mathrm{Hg}$ exposure, indirectly, showed that water movement within the seedlings was not disturbed by $\mathrm{Hg}$ application. Therefore, nutrients distribution (especially $\mathrm{P}, \mathrm{Ca}$ and $\mathrm{Mg}$ ) in $\mathrm{N}$. orientalis seedlings were not inhibited. In reference [5] stated that the increase of some nutrients in response to trace toxic elements could be a strategy to avoid toxicity in plants, although a contribution of concentration effects after $\mathrm{Hg}$ application cannot be ruled out. The role of AM fungi in the increase of plant nutrients could also be an important strategy to enhance the resistance to $\mathrm{Hg}$ stress.

Table 4. Ca and Mg uptake and translocation in $\mathrm{N}$. orientalis seedlings grown for 30 days in river sands treated with different Hg concentrations and mycorrhizal inoculation.

\begin{tabular}{|c|c|c|c|c|}
\hline \multirow{2}{*}{ Hg $(\mu \mathrm{M})$} & \multicolumn{4}{|c|}{ Arbuscular mycorrhizal inoculation } \\
\hline & Without & With & Without & With \\
\hline & \multicolumn{2}{|c|}{ Ca uptake (nmol $\left.\mathrm{Hg} \mathrm{g}^{-1} \mathrm{DW}\right)$} & \multicolumn{2}{|c|}{ Ca translocation (nmol $\mathrm{Hg} \mathrm{g}^{-1} \mathrm{DW}$ ) } \\
\hline 0 & $55.3 \pm 2.2 \mathrm{~b}$ & $53.4 \pm 3.7 b c$ & $94.8 \pm 4.5 b$ & $96.7 \pm 13.1 b$ \\
\hline 375 & $42.0 \pm 2.5 \mathrm{~d}$ & $44.5 \pm 0.9 \mathrm{~cd}$ & $80.4 \pm 7.7 b$ & $90.0 \pm 3.3 b$ \\
\hline \multirow[t]{2}{*}{750} & $41.8 \pm 5.0 \mathrm{~d}$ & $67.5 \pm 1.5 \mathrm{a}$ & $79.3 \pm 9.4 b$ & $136.5 \pm 12.6 \mathrm{a}$ \\
\hline & \multicolumn{2}{|c|}{ Mg uptake (nmol $\left.\mathrm{Hg} \mathrm{g}^{-1} \mathrm{DW}\right)$} & \multicolumn{2}{|c|}{ Mg translocation $\left(\mathrm{nmol} \mathrm{Hg} \mathrm{g}^{-1} \mathrm{DW}\right)$} \\
\hline 0 & $16.7 \pm 1.3 b$ & $16.2 \pm 0.6 b$ & $78.0 \pm 7.1 \mathrm{~b}$ & $79.4 \pm 8.1 b$ \\
\hline 375 & $16.5 \pm 1.5 b$ & $17.7 \pm 0.2 b$ & $85.1 \pm 3.0 \mathrm{~b}$ & $97.2 \pm 3.0 \mathrm{~b}$ \\
\hline 750 & $15.9 \pm 0.4 b$ & $24.1 \pm 1.2 \mathrm{a}$ & $82.7 \pm 7.6 b$ & $131.9 \pm 10.3 \mathrm{a}$ \\
\hline
\end{tabular}

Significant differences among $\mathrm{Hg}$ treatments are indicated by different letter (mean $\pm \mathrm{SE}, \mathrm{n}=3$; LSD's test, $\mathrm{p}<0.05$ )

\subsection{Effect of Mercury and Arbuscular Mycorrhizal Fungi on Chlorophyll and Lipid Peroxidation}

Chlorophylls and MDA have been used as biomarkers, which can be used in the early diagnosis of metal toxicity [45]. Mercury inhibits enzymes involved in chlorophyll synthesis [46] and consequently, reduced chlorophyll levels have been observed [4]. In this research, chlorophyll (a, b and total) concentration in $N$. orientalis seedlings remained unchanged during exposure to $\mathrm{Hg}$ treatment (data not shown). This means that the process of photosynthesis was not impaired by $\mathrm{Hg}$ up to $750 \mu \mathrm{M}$ on river sands media. This result was contrasts with research as in [5] which chlorophyll a concentration in $R$. induratus and $M$. vulgare were decreased significantly, while chlorophyll b levels remained unchanged by 5,10 , and $50 \mu \mathrm{M} \mathrm{Hg}$ rates when cultivated after $\mathrm{Hg}$ exposure for 2 months. There were not toxicity symptoms in leaves of $N$. orientalis seedlings during 30 days of $\mathrm{Hg}$ exposure. Enhancement of chlorophyll b concentration was observed in $N$. orientalis seedlings inoculated with AM fungi (Fig. 2). AM fungi resulted in significant increased chlorophyll b concentration by $15 \%$ when compared to the control (non-mycorrhiza). Increased chlorophyll b concentration could increase the accessory pigment that collects the energy to pass on to chlorophyll a.

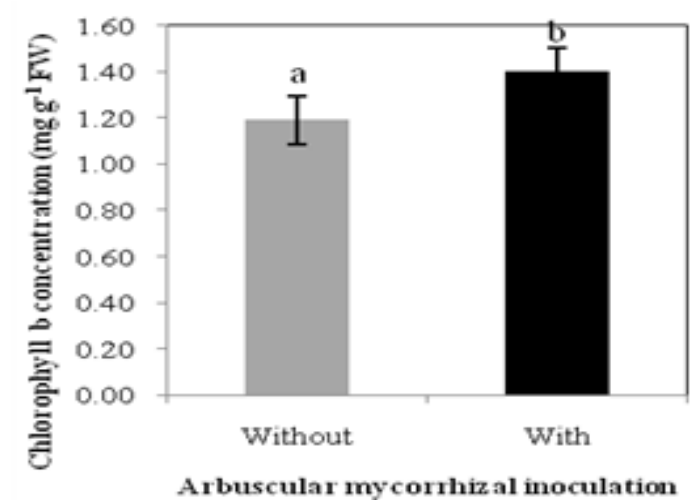

Figure 2. Chlorophyll $b$ concentration of seedlings inoculated with arbuscular mycorrhiza (mean $\pm S E, n=9$ ). Significant difference for each $A M$ inoculation treatments are indicated by different letter (LSD's test, $p<0.05)$.

Exposure of plants to non-redox-reactive heavy metal, such as $\mathrm{Hg}$, resulted in oxidative stress as indicated by lipid peroxidation, $\mathrm{H}_{2} \mathrm{O}_{2}$ accumulation, and an oxidative burst [47]. Lipid peroxidation reflected the toxic effects of $\mathrm{Hg}$ on the cell membrane in tissues [7]. In this research, only 
malondialdehyde (MDA) was measured as a variable of lipid peroxidation. Roots of $N$. orientalis seedlings did not show any significantly increased in lipid peroxidation when $\mathrm{Hg}$ treatment is applied as a single factor (data not shown). It showed that oxidative stress was not observed in roots with $\mathrm{Hg}$ application, even though $\mathrm{Hg}$ was accumulated in roots. On the other hand, MDA concentration in roots of mycorrhizal seedlings was significantly decreased by $76 \%$ when it was compared to the control (non-mycorrhizal) (Fig. 3). It means that lipid peroxidation was reduced by AM fungi, consequently, the oxidative stress in roots could be minimized.

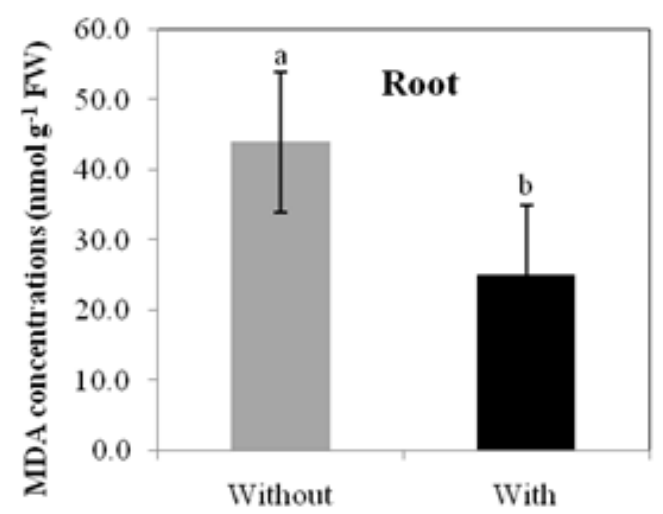

Arbuscular mycorrhizal inoculation

Figure 3. MDA concentration in roots of seedlings inoculated with arbuscular mycorrhiza (mean $\pm S E, n=9$ ). Significant difference among $A M$ inoculation treatments are indicated by different letter (LSD's test, $p<0.05$ ).

In contrast to MDA concentration in roots, MDA concentration in leaves of $N$. orientalis seedlings was significantly affected by combined effects of $\mathrm{Hg}$ application and $\mathrm{AM}$ inoculation (Fig. 4). At the $0 \mu \mathrm{M}$ and $375 \mu \mathrm{M} \mathrm{Hg}$ concentration, MDA concentration witin leaves of mycorrhizal seedlings were higher than within non-mycorrhizal seedlings, but they did not differ significantly with the MDA concentration in leaves of mycorrhizal seedlings at the $750 \mu \mathrm{M} \mathrm{Hg}$ concentration.

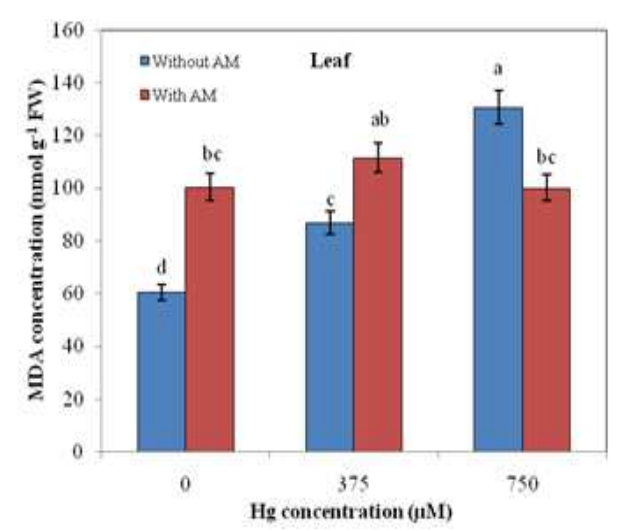

Figure 4. MDA concentration in leaves of $N$. orientalis seedlings with different $\mathrm{Hg}$ concentration (mean $\pm S E, n=3$ ). Significant difference among $\mathrm{Hg}$ treatments are indicated by different letter (LSD's test, $p<0.05$ ).
It indicates that the inoculation of AM fungi to $N$. orientalis seedlings minimized the increased of lipid peroxidation when $\mathrm{Hg}$ concentration was increased. However, in non-mycorrhizal seedlings, MDA concentration in leaves increased with increased $\mathrm{Hg}$ concentration. At the highest concentration of $\mathrm{Hg}, \mathrm{MDA}$ concentration in leaves of non-mycorrhizal plants was increased significantly by $116 \%$ compared to the mycorrhizal plants. In line with this, MDA levels in tomato plant tissues increase in response to $\mathrm{Hg}$ [4] as a consequence of higher lipid peroxidation. Although there was the significant increase of MDA concentration, it did not cause toxicity in non-mycorrhizal seedlings. It reveal that $N$. orientalis is included $\mathrm{Hg}$ tolerance species.

\section{Conclusions}

A major part of $\mathrm{Hg}$ accumulated by $N$. orientalis seedlings was in root. Translocation of $\mathrm{Hg}$ to the aerial part of the plant (leaves) was limited so that the contents were relatively constant even though the $\mathrm{Hg}$ concentration in the growth media was higher. Mycorrhizal symbiosis showed a significant effect of the resistance to $\mathrm{Hg}$ stress of $N$. orientalis plants grown in $\mathrm{Hg}$ treated and non-treated $\mathrm{Hg}$ media. $N$. orientalis seedlings have a high tolerance to $\mathrm{Hg}$ exposure $(>70 \%)$. The recently results indicate the potential of $N$. orientalis and AM fungi to be used in the long-term land reclamation strategy, including land use purposes beneficial in areas $\mathrm{Hg}$-polluted.

\section{Acknowledgements}

We thanks to the Southeast Asian Regional Centre for Tropical Biology (SEAMEO BIOTROP), thesis research grants for 2012, financially supported this research.

\section{References}

[1] [ATSDR] Agency for Toxic Substances and Disease Registry, [Internet], The Priority List of Hazardous Subtances that Will Be the Subject of Toxicological Profiles. Atlanta, Georgia (US): Department of Health and Human Services, 2013. [cited 2013 August 30]. Available from http://www.atsdr.cdc.gov/SPL/index.html.

[2] [M Patra, A Sharma, Mercury toxicity in plants, Bot Rev, Vol. 66, pp. 379-422, 2000.

[3] J. Sobrino-Plata, C. Ortega-Villasante, M.L. Flores-Cáceres, C. Escobar, F.F. Del Campo, L.E. Hernández, Differential alterations of antioxidant defenses as bioindicators of mercury and cadmium toxicity in alfalfa, Chemosphere, Vol. 77, pp. 946-954, 2009.

[4] U.H. Cho, J.O. Park, Mercury-induced oxidative stress in tomato seedlings, Plant Sci, Vol. 156, pp. 1-9, 2000.

[5] E. Moreno-Jiménez, J.M. Penalosa, E. Esteban, R.O. Carpena, Mercury accumulation and resistance to mercury stress in Rumex induratus and Marrubium vulgare grown on perlite, J Plant Nutr Soil Sci, Vol. 170, pp. 485-494, 2007. 
[6] S. Shiyab, J. Chen J, F.X. Han, D.L. Monts, F.B. Matta, M. $\mathrm{Gu}, \mathrm{Y} . \mathrm{Su}$, Phytotoxicity of mercury in Indian mustard (Brassica juncea L.), Ecotoxicology and Environmental Safety, Vol. 72, pp. 619-625, 2009. DOI:10.1016/j.ecoenv.2008.06.002.

[7] J. Chen, S. Shiyab, F.X. Han, D.L. Monts, C.A. Waggoner, Z.M. Yang, Y. Su, Bioaccumulation and physiological effects of mercury in Pteris vittata and Nephrolepsis exaltata. Ecotoxocology, Vol. 18(1), pp. 110-121, 2009. DOI 10.1007/s10646-008-0264-3.

[8] D.E. Salt, M. Blaylock, N.P.B.A. Kumar, V. Dushenkov, B.D. Ensley, I. Chet I, I. Raskin, Phytoremediation: a novel strategy for the removal of toxic metals total carotenoids, using various solvents with spectrophotometers of different from the environment using plants, Biotechnology, Vol. 13, pp. 468-474, 1995.

[9] B.H. Robinson, R. Schulin, B. Nowack, S. Roulier, M. Menon, B.E. Clothier, S.R. Green, T.M. Mills, Phytoremediation for the management of metal flux in contaminated sites, Forest Snow Landscape Res, Vol. 80(2), pp. 221-234, 2006.

[10] I.D. Pulford, N.M. Dickinson, "Phytoremediation Technologies Using Trees", in Trace elements in the environment, M.N.V. Prasad, K.S. Saiwan, R. Naidu, Eds. New York: Taylor and Francis, CRC Press, pp. 375-395, 2005.

[11] M. Greger, Y. Wang, C. Neuschútz, Absence of $\mathrm{Hg}$ transpiration by shoot after $\mathrm{Hg}$ uptake by roots of six terrestrial plant species, Environmental Pollution, Vol. 134, pp. 201-208, 2005.

[12] C. Ortega-Villasante, R. Rellán-Alvarez, F.F. Del Campo, R.O. Carpena Ruiz, L.E. Hernández, Cellular damage induced by cadmium and mercury in Medicago sativa, Journal of Experimental Botany, Vol. 56, pp. 2239-2251, 2005 .

[13] L. Rodríguez, J. Rincón, I. Asencio, L. Rodríguez-Castellanos, Capability of selected crop plants for shoot mercury accumulation from polluted soils: Phytoremediation perspectives, International Journal of Phytoremediation, Vol. 9, pp. 1-13, 2007.

[14] M.J. Sierra, R. Millán, E. Esteban, A.I. Cardona, T. Schmid, Evaluation of mercury uptake and distribution in Vicia sativa L. applying two different study scales: Greenhouse conditions and lysimeter experiments, Journal of Geochemical Exploration, Vol. 96, pp. 203-209, 2008.

[15] World Agroforestry Centre, A tree species reference and selection guide. AgroForestryTree Database, PROSEA,http://www.worldagroforestrycentre.org/sea/produ cts/afdbases/af/asp/SpeciesInfo.asp?SpID=17928. [cited March 13, 2012]

[16] S.E. Smith, D.J. Read, Mycorrhial Symbiosis. 3rd ed., Great Britain: Academic Press, 2008.

[17] M.C. Gonzalez-Chavez, S.F. Wright, K.A. Nichols, The role of glomalin, a protein produced by arbuscular mycorrhizal fungi, in sequestering potentially toxic elements, Environmental Pollution, Vol. 130, pp. 317-323, 2004.

[18] M. Janoušková, D. Pavlíková, M. Vosátka, Potential contribution of arbuscular mycorrhiza to cadmium immobilisation in soil, Chemosphere, Vol. 65, pp. 1959-1965, 2006.
[19] A.P.G.C. Marques, R.S. Oliveira, A.O.S.S. Rangel, P.M.L. Castro, Zinc accumulation in Solanum nigrum is enhanced by different arbuscular mycorrhizal fungi, Chemosphere, Vol. 65, pp. 1256-1263, 2006.

[20] Y. Yu, S. Zhang, H. Huang, Behavior of mercury in a soil-plant system as affected by inoculation with the arbuscular mycorrhizal fungus Glomus mosseae, Mycorrhiza, Vol. 20, 407-414, 2010.

[21] P. Zornoza, R. Millan, M.J. Sierra, A. Seco, E. Esteban, Efficiency of white lupin in removal of mercury from contaminated soils: Soil and hydroponic experiments, Journal of Environmental Sciences, Vol. 22(3), pp. 421-427, 2010.

[22] F.X.X. Han, A. Banin, Y. Su, D.L. Monts, M.J. Plodinec, W.L. Kingery, G.E. Triplett, Industrial age anthropogenic inputs of heavy metals into the pedosphere, Naturwissenschaften, Vol. 89: 497-504, 2002.

[23] D.I. Arnon, Copper enzymes in isolated chloroplast. Polyphenoloxidase in Beta vulgaris. Plant Physiol, Vol. 24, pp. 1-15, 1949.

[24] M. Brundrett, N. Bougher, B. Dell, T. Grove, N. Malajczuk, Working with Mycorrhizas in Forestry and Agriculture. ACIAR Monograph 32. 374 + x p., 1996.

[25] Y. Wang, M. Greger, Plant and environment interactions: Clonal differences in mercury tolerance, accumulation, and distribution in willow, J Environ Qual, Vol. 33, pp. 1779-1785, 2004.

[26] G.H. Rabie, Contribution of arbuscular mycorrhizal fungus to red kidney and wheat plants tolerance grown in heavy metal-polluted soil. African Journal of Biotechnology, Vol. 4(4), pp. 332-345, 2005.

[27] S. Iglesia-Turiño, A. Febrero, O. Jauregui, C. Caldelas, J.L. Araus, J. Bort, Detection and quantification of unbound phytochelatin 2 in plant extracts of Brassica napus grown with different levels of mercury, Plant Physiology, Vol. 142, pp. 742-749, 2006.

[28] R. Rellán-Álvarez, C. Ortega-Villasante, A. Álvarez-Fernández, F.F. del Campo, L. E. Hernández, Stress responses of Zea mays to cadmium and mercury, Plant and Soil, Vol. 279, pp. 41-50, 2006.

[29] M. Kaldorf, A. J. Kuhn, W.H. Schrőder, U. Hildebrandt, H. Bothe, Selective element deposits in maize colonized by a heavy metal tolerance conferring arbuscular mycorrhizal fungus, J Plant Physiol, Vol 154, pp. 718-728, 1999.

[30] E.J. Joner, R. Briones, C. Leyval, Metal-binding capacity of arbuscular mycorrhizal mycelium, Plant Soil, Vol. 226, pp. $227-234,2000$

[31] G. Rufyikiri, S. Declerck, J.E. Dufey, Arbuscular mycorrhizal fungi might alleviate aluminium toxicity in banana plants, New Phytol, Vol. 148(2), pp. 343-352, 2000.

[32] X. Yu, J. Cheng, M.H. Wong, Earthworm-mycorrhiza interaction on Cd uptake and growth of ryegrass, Soil Biol Biochem, Vol. 37, pp. 1-7, 2004.

[33] S.H. Burleigh, B.K. Kristensen, I.E. Bechmann, A plasma membrane zinc transporter from Medicago truncatula is upregulated in roots by $\mathrm{Zn}$ fertilization, yet down - regulated by arbuscular mycorrhizal colonization, Plant Mol Biol, Vol. 52(5), pp. 1077-1088, 2003. 
[34] R. Malcova, M. Vosatka, M. Gryndler, Effects of inoculation with Glomus intraradices on lead uptake by Zea mays L. and Agrostis capillaris L., Appl Soil Ecol, Vol. 23(1), pp. 255-267, 2003.

[35] G. Rufyikiri, L. Huysmans, J. Wannijn, M. van Hees, C. Leyval, I. Jakobsen, Arbuscular mycorrhizal fungi can decrease the uptake of uranium by subterranean clover grown at high levels of uranium in soil, Environ Pollut, Vol. 130, pp. 427-436, 2004.

[36] Y. Yu, S.Z. Zhang, H. L. Huang, L. Luo, B. Wen, Arsenic accumulation and speciation in maize as affected by inoculation with arbuscular mycorrhizal fungus Glomus mosseae, J Agr Food Chem, Vol. 57, pp. 3695-3701, 2009.

[37] M. Válega, A. I. G. Lima, E. M. A. P. Figueira, E. Pereira, M.A. Pardal, A.C. Duarte, Mercury intracellular partitioning and chelation in a salt marsh plant, Halimione portulacoides (L.) Aellen: strategies underlying tolerance in environmental exposure, Chemosphere, Vol. 74, pp. 530-536, 2009.

[38] J.A. Ericksen, M.S. Gustin, Foliar exchange of mercury as a function of soil and air mercury concentrations, Sci Total Environ, Vol. 324, pp. 271-279, 2004.

[39] L. Fay, M. Gustin, Assessing the influence of different atmospheric and soil mercury concentrations on foliar mercury concentrations in a controlled environment, Water Air Soil Poll, Vol. 181, pp. 373-384, 2007.

[40] E. Lozano-Rodríguez, L. E. Hernández, P. Bonay, Distribution of cadmium in shoots and root tissues of maize and pea plants: physiological disturbances, Journal Experimental Botany, Vol. 48, pp. 123-128, 1997.

[41] A. Schützendübel, P. Schwanz, T. Teichmann, K. Gross, R.
Langenfeld-Heyser, D.L. Goldbold, A. Polle, Cadmium-induced changes in antioxidant systems, hydrogen peroxide content and differentiation in Scot pine roots, Plant Physiol, Vol. 127, pp. 887-898, 2001.

[42] L. E. Hernández, C. Ortega-Villasante, M. B. Montero-Palmero, "Heavy Metal Perception in a Microscale Environment: A Model System Using High Doses of Pollutants", in: Metal Toxicity in Plants: Perception, Signaling and Remediation, D. K. Gupta, L. M. Sandalio, Eds. Berlin Heidelberg: Springer-Verlag, 2012. DOI 10.1007/978-3-642-22081-4_2.

[43] U. Hildebrandt, M. Regvar, H. Bothe, Arbuscular mycorrhiza and heavy metal tolerance, Phytochemistry, Vol. 68, pp. 139-146, 2007.

[44] S. Cheng, Effects of Heavy Metals on Plants and Resistance Mechanisms. A State-of-the-Art Report with Special Reference to Literature Published in Chinese Journals. ESPR- Environ Sci \& Pollut Res, Vol. 10(4), pp. 256-264, 2003. DOI http://dx.doi.or 10.1065/espr2002.11.141.

[45] M. N. V. Prasad, "Biomarkers", in Heavy Metal Stress in Plants. From Molecules to Ecosystem, 2nd ed., M. N. V. Prasad, J. Hagemeyer, Eds. Berlin: Springer-Verlag, pp. 445-448, 2003.

[46] D. D. K. Prasad, A. R. K. Prasad, Altered d-aminolevulinic acid metabolism by lead and mercury in germinating seedlings of bajra (Pennisetum typhoideum), J Plant Physiol, Vol. 127, pp. 241-249, 1987.

[47] A. Schützendübel, A. Polle, Plant responses to abiotic stresses: heavy metal-induced oxidative stress and protection by mycorrhization, J Exp Bot, Vol. 53, pp. 1351-1365, 2002. 